\title{
Acute effect of oral sildenafil on diffusion capacity measurements in patients with diffuse parenchymal lung disease and pulmonary hypertension
}

\author{
Isabel Mira-Avendano ${ }^{1 *}$, Umur Hatipoğlu ${ }^{1}$, Catherine Sant ${ }^{1}$, Daniel Laskowski ${ }^{1}$, Ruchi Yadav ${ }^{2}$ and Raed Dweik $^{1}$ \\ ${ }^{1}$ Respiratory Institute, Cleveland Clinic, Cleveland, USA \\ ${ }^{2}$ Imaging Institute, Cleveland Clinic, Cleveland, USA
}

\begin{abstract}
Diffuse parenchymal lung diseases have diverse etiology and treatment often requires individualization taking into consideration comorbidities. Pulmonary hypertension represents one such comorbidity which, when present, worsens prognosis and confounds approach to treatment. Sildenafil is a pulmonary vasodilator, which has recently generated considerable interest for use in patients with diffuse parenchymal lung disease and concomitant pulmonary hypertension.

We wondered whether acute administration of oral sildenafil affects the diffusion capacity measurement, which is a tool for serially monitoring patients with diffuse parenchymal lung diseases.

Methods: 15 patients with diffuse parenchymal lung disease and pulmonary hypertension (WHO Class III) had diffusion capacity measurements and 6-minute walk test performed before and after receiving sildenafil $20 \mathrm{mg}$ orally. CT scans of the chest were scored to determine burden of interstitial lung disease.

Results: The mean change in DLCO after administration of oral sildenafil was $-0.26 \pm 0.94 \mathrm{ml} / \mathrm{min} / \mathrm{mmHg}(\mathrm{p}=0.30)$ and $-0.41 \pm 2.84 \% \mathrm{predicted}(\mathrm{p}=0.58)$. The average 6minute walk distance at baseline was $1195 \pm 407$ feet. After oral administration of sildenafil, 6minute walk distance was $1214 \pm 383$ feet ( $\mathrm{p}=0.63$ ). No correlation was observed between composite radiology scores and DLCO measurements or change in DLCO and radiology scores ( $\mathrm{p}=0.43$ and $\mathrm{p}=0.17$ respectively).

Conclusion: We found no acute change in diffusion capacity after a single dose of oral sildenafil in patients with diffuse parenchymal lung disease and pulmonary hypertension.
\end{abstract}

\section{Introduction}

Diffuse parenchymal lung diseases have diverse etiology and treatment often requires individualization taking into consideration comorbidities. Pulmonary hypertension represents one such comorbidity which, when present, worsens prognosis $[1,2]$ and confounds approach to treatment. Furthermore, with the exception of pulmonary hypertension in the setting of connective tissue diseaserelated parenchymal lung disease, there is controversy in the utility of treatment of pulmonary hypertension in this group of patients (WHO Group III).

Sildenafil is a cyclic GMP selective phosphodiesterase type 5 inhibitor approved for use in patients with pulmonary arterial hypertension. The drug has recently generated considerable interest for use in patients with diffuse parenchymal lung disease and concomitant pulmonary hypertension. A theoretical concern has been the possible worsening in oxygenation when pulmonary vasodilators are introduced to patients with abnormal ventilation perfusion matching at baseline. In a small, but meticulously conducted physiological studies, sildenafil has shown salutary effects with improvement in pulmonary pressures with negligible impact on oxygenation and ventilation perfusion mismatch [3]. In a post hoc subgroup analysis of 84 patients with pulmonary arterial hypertension and connective tissue disease who had been included in the SUPER-1 trial, Badesch and colleagues demonstrated improvements in exercise capacity, hemodynamic changes and functional class, following 12 weeks of treatment with varying doses of sildenafil [4]. Later, 259 patients from the SUPER-1 trial were enrolled in an open label extension study (SUPER-2) of 3 years duration which demonstrated continued improvement or maintenance of functional status while on sildenafil [5]. Recently, sildenafil was associated with small but statistically significant improvements in diffusion capacity and oxygenation while having no effect on 6 minute walk distance in 180 patients with advanced idiopathic pulmonary fibrosis and pulmonary hypertension [6]. Diffusion capacity of the lung for carbon monoxide (DLCO) measurement is ubiquitously available and is used as a tool for serially monitoring patients with diffuse parenchymal lung diseases. The American Thoracic Society has endorsed its use in the assessment of patients with idiopathic interstitial pneumonias [7]. Diffusion capacity measurements are affected by blood volume and transit time in the capillary bed. Therefore, pulmonary vasodilators can potentially affect measurements by altering pulmonary vascular hemodynamics. The aim of our study was to determine the acute effect of oral sildenafil on diffusion capacity in patients with diffuse parenchymal lung disease and concomitant pulmonary hypertension.

Correspondence to: Isabel Mira-Avendano, Mayo clinic, North America, Email: Mira.Isabel@mayo.edu

Key words: pulmonary hypertension, parenchymal lung disease, diffusion capacity

Received: October 03, 2017; Accepted: October 24, 2017; Published: October 27,2017 
Mira-Avendano I (2017) Acute effect of oral sildenafil on diffusion capacity measurements in patients with diffuse parenchymal lung disease and pulmonary hypertension

The significance of this information is twofold. First, it would be helpful clinically to determine the contribution of a pulmonary vasodilator to the change in DLCO to separate this effect from a change in the clinical status of parenchymal disease. Second, sildenafil's effect on gas exchange may lead to modifications in therapy such as changes in oxygen flow delivered to patients.

\section{Study population}

Adult patients over age 18 years of age, who were able to consent and had received a diagnosis of diffuse parenchymal lung disease with concomitant pulmonary hypertension, were eligible. The diagnosis of diffuse parenchymal lung disease was made by the primary pulmonologist based on clinical presentation, high resolution chest CT findings and presence of restrictive or mixed pattern in spirometry. The diagnosis of pulmonary hypertension was based on echocardiographic findings and/or invasive hemodynamic measurement (estimated RVSP $35 \mathrm{~mm} \mathrm{Hg}$ or more, or mean pulmonary artery pressure over 25 $\mathrm{mmHg}$ with pulmonary capillary wedge pressure less than $15 \mathrm{~mm} \mathrm{Hg}$, respectively).

\section{Materials and methods}

The study was approved by the Institutional Review Board of the Cleveland Clinic. Informed consent was obtained from each patient. Assuming 15\% change in DLCO representing a significant clinical difference and a standard deviation of $17.4 \%$ in normal nonsmoking individuals [8], 13 subjects needed to be studied to reject the null hypothesis when there is no significant difference between DLCO measurements before and after sildenafil, with power 0.8 and type I error probability 0.05 (SAS 9.2, SAS Institute Inc., Cary, NC) METHODS: Diffusing capacity of the lung for carbon monoxide Measurement of the diffusing capacity of the lung for carbon monoxide (DLCO) was performed on the Jaeger Masterscreen Body PFT unit (CareFusion, Inc., Yorba Linda, CA) in accordance with the 2005 ATS/ERS recommendations for a standard single-breath technique [9]. Measurements were performed in duplicate (or more if expected laboratory standard for DLCO repeatability of $<10 \%$ or $3 \mathrm{~mL} / \mathrm{min} /$ $\mathrm{mmHg}$ was not met) and the mean value for single-breath DLCO, DLCO/VA and VA were reported.

6 minute walk: Six minute walk was performed in accordance with ATS guidelines [10]. In brief, the patient sat at rest in a chair, located near the starting position, for at least 10 minutes before the test. Time in was started as soon as the patient started to walk. Standard phrases of encouragement were used during the walk. The total distance walked was calculated by counting the laps and rounding to the nearest meter.

High resolution chest tomography: Radiology score Computed tomography (CT) scan of the chest studies which were ordered at the discretion of the treating physician were interpreted when available. Imaging studies which were within 6 months of DLCO measurements were included. A radiological scoring system for idiopathic pulmonary fibrosis [11] was employed for the study protocol. A radiologist with expertise in thoracic radiology (R.Y.), who was blinded to patient history and research protocol, scored all available images. Scores for groundglass opacity (GGO) and fibrosis were obtained. The GGO and fibrosis scores were added to create a composite score that reflected disease burden.

Protocol: Baseline FVC, FEV , TLC (all within the past 6 months of study recruitment), $\mathrm{O}_{2}$ flow if any, were obtained from patient's medical record. Radiology score was calculated for each patient for whom high resolution CT scan of the chest was available. Then, each patient underwent diffusion capacity measurement, and 6 minute walk. After baseline measurements, $20 \mathrm{mg}$ of oral sildenafil was administered. Following one hour of rest, DLCO measurement and 6 minute walk were repeated.

Analysis: Paired t-test was used to assess the change in DLCO before and after sildenafil. Spearman correlation coefficients and respective $\mathrm{p}$-values were derived to assess the correlation between diffusion capacity measurements, pulmonary function test variables and imaging scores using statistical software (SAS 9.2, SAS Institute Inc., Cary, NC).

\section{Results}

\section{Patients}

Fifteen ( 7 female, 8 male) with diffuse parenchymal lung disease and concomitant pulmonary hypertension were enrolled in the study. Average age was $58.6 \pm 13$ years. Six patients had idiopathic pulmonary fibrosis, four had usual interstitial pneumonia (associated with mixed connective tissue disease, undifferentiated connective tissue disease, systemic sclerosis and rheumatoid arthritis), three had nonspecific interstitial pneumonia ( 2 associated with systemic sclerosis, and one with mixed connective tissue disease), one had sarcoidosis and one had chronic hypersensitivity pneumonitis. Patient characteristics are summarized in [Table 1].

DLCO: The mean DLCO before sildenafil was $9.33 \pm 3.72 \mathrm{ml} /$ $\mathrm{min} / \mathrm{mmHg}$ (35.7\% predicted), and post Sildenafil was $9.07 \pm 3.77 \mathrm{ml} /$ $\mathrm{min} / \mathrm{mmHg}$ (35.29\% predicted). DLCO before and after sildenafil administration for all patients is shown in figure 1.

The mean change in DLCO after administration of oral sildenafil was $-0.26 \pm 0.94 \mathrm{ml} / \mathrm{min} / \mathrm{mmHg}(\mathrm{p}=0.30)$ and $-0.41 \pm 2.84 \%$ predicted $(\mathrm{p}=0.58)$ [Table 2].

6-minute walk distance: The average 6-minute walk distance at baseline was $1195 \pm 407$ feet. After oral administration of sildenafil, 6 minute walk distance was $1214 \pm 383$ feet $(\mathrm{p}=0.63)$.

None of the patients required adjustment of their oxygen flow during the 6 minute walk after sildenafil administration (data not shown).

\section{Association between DLCO before and after sildenafil and other variables}

There was not statistically significant correlation between DLCO before and after sildenafil and radiology scores. The Spearman correlation coefficient between the HRCT ground glass score and DLCO (in $\mathrm{ml} / \mathrm{min} / \mathrm{mmHg}$ and as \% predicted) pre-sildenafil was $-0.42(\mathrm{p}=0.12)$ and $-0.23 \%(\mathrm{p}=0.40)$, respectively. After sildenafil, the coefficients were -0.38 (DLCO in $\mathrm{ml} / \mathrm{min} / \mathrm{mmHg})(\mathrm{p}=0.16)$ and $-0.22 \%$ (DLCO as \% predicted) $(\mathrm{P}=0.44)$. Correlation coefficients between radiologic fibrosis score and DLCO before and after sildenafil were 0.32 (DLCO in $\mathrm{ml} / \mathrm{min} / \mathrm{mmHg})(\mathrm{p}=0.24), 0.04$ (DLCO as \% predicted) $(\mathrm{p}=0.89)$ and $0.13(\mathrm{DLCO}$ in $\mathrm{ml} / \mathrm{min} / \mathrm{mmHg})(\mathrm{p}=0.63),-0.07$ (DLCO as $\%$ predicted $)(\mathrm{p}=0.79)$. Similarly, no correlation was observed between composite radiology scores and DLCO measurements or change in DLCO and radiology scores [Table 3].

Correlation between FVC (L and \% predicted) and radiologic score was $-0.23(\mathrm{p}=0.42)$ and $-0.07(\mathrm{p}=0.8)$ respectively for GGO, $(0.03$ $(\mathrm{p}=0.9)$ and $-0.32(\mathrm{p}=0.25)$ for fibrosis. Composite radiology scores and DLCO measurements were not significantly correlated, either [Table 4]. 
Mira-Avendano I (2017) Acute effect of oral sildenafil on diffusion capacity measurements in patients with diffuse parenchymal lung disease and pulmonary hypertension

Table 1. Patient characteristics

\begin{tabular}{|c|c|c|c|c|c|c|c|c|c|}
\hline Patient & Age & Gender & Diagnostic & $\begin{array}{l}\text { Diagnostic } \\
\text { test for PH }\end{array}$ & $\operatorname{FVC(L)}$ & FVC (\%) & $\begin{array}{c}\text { DLCO } \\
(\mathrm{ml} / \mathrm{mmHg} / \mathrm{m})\end{array}$ & $\begin{array}{c}\text { DLCO } \\
(\%)\end{array}$ & $\begin{array}{c}\text { 6MWT } \\
\text { (ft) }\end{array}$ \\
\hline 1 & 48 & $\mathrm{M}$ & IPF & RHC & 1.15 & 25 & 5.6 & 21 & 156 \\
\hline 2 & 47 & $\mathrm{~F}$ & IPF & RHC & 1.31 & 30 & 7.7 & 18 & 720 \\
\hline 3 & 58 & $\mathrm{~F}$ & HP & TTE & 1.32 & 37 & 5.2 & 20 & 1330 \\
\hline 4 & 43 & $\mathrm{~F}$ & MCTD/UIP & RHC & 1.38 & 40 & 6.6 & 29 & 1550 \\
\hline 5 & 63 & $\mathrm{~F}$ & UCT/UIP & RHC & 1.94 & 67 & 8.2 & 38 & 1215 \\
\hline 6 & 60 & M & SS/UIP & RHC & 2.19 & 44 & 12.9 & 44 & 1360 \\
\hline 7 & 74 & $\mathrm{M}$ & IPF & RHC & 2.24 & 67 & 8.5 & 37 & 882 \\
\hline 8 & 49 & $\mathrm{~F}$ & SS/NSIP & RHC & 2.78 & 85 & 10.3 & 46 & 1805 \\
\hline 9 & 47 & $\mathrm{~F}$ & MCT/NSIP & RHC & 2.81 & 82 & 6.9 & 30 & 1250 \\
\hline 10 & 81 & M & RA/UIP & TTE & 2.95 & 66 & 7.5 & 33 & 1020 \\
\hline 11 & 48 & $\mathrm{~F}$ & SS/NSIP & TTE & 3.01 & 75 & 11.5 & 47 & 1660 \\
\hline 12 & 70 & M & IPF & RHC & 3.03 & 64 & 10.9 & 41 & 1470 \\
\hline 13 & 83 & $\mathrm{M}$ & IPF & TTE & 3.73 & 93 & 8.5 & 34 & 1075 \\
\hline 14 & 61 & M & SAR & RHC & 4.63 & 97 & 20.3 & 64 & 1350 \\
\hline 15 & 63 & M & IPF & RHC & 2.37 & 48 & 9.4 & 33 & 1090 \\
\hline
\end{tabular}

P: patient / IPF: Idiopathic pulmonary fibrosis / MCTD Mixed connective tissue disease / UDCT Undifferentiated connective tissue disease / ILD Dx diagnosis of interstitial lung disease / PH Dx: Method used to diagnose pulmonary hypertension / SS: Systemic scleroderma / UIP: Usual interstitial pneumonia / SAR: Sarcoidosis / HRCT: High resolution CT / GGO: Ground Glass opacity / HRCT Total/ Combined radiologic score (GGO+Fibrosis) / 6MWT 6 minutes walking test

All the patients were able to sign a consent form, authorizing publication of all the data presented in this table.

Table 2. Change in DLCO Pre and Post Sildenafil $(n=15)$

\begin{tabular}{|c|c|c|c|c|}
\hline $\begin{array}{c}\text { DLCO PRE } \\
\text { SILDENAFIL } \\
(\mathbf{m l} / \mathbf{m i n} / \mathbf{m m H g})\end{array}$ & $\begin{array}{c}\text { DLCO POST } \\
\text { SILDENAFIL } \\
\text { (ml/min/mmHg) }\end{array}$ & $\begin{array}{c}\text { DLCO } \\
\text { CHANGE }\end{array}$ & P value \\
\hline Total & 9.33 & 9.07 & -0.26 \\
\hline Percentage & 35.7 & 35.29 & -0.41 \\
\hline
\end{tabular}

Table 3. Spearman correlation coefficient between DLCO pre- and post sildenafil and HRCT radiology score

\begin{tabular}{|c|c|c|c|c|c|c|c|c|}
\hline DLCO Pre & $\mathbf{p}$ & DLCO post & P & $\begin{array}{c}\text { DLCO (\% } \\
\text { predicted pre) }\end{array}$ & P & $\begin{array}{c}\text { DLCO (\% } \\
\text { predicted } \\
\text { Post) }\end{array}$ & $\begin{array}{c}\text { Phange in } \\
\text { DLCO }\end{array}$ & -0.22 \\
\hline $\begin{array}{c}\text { HRCT GGO } \\
\text { Score }\end{array}$ & -0.42 & 0.12 & -0.38 & 0.16 & -0.23 & 0.40 & 0.44 \\
\hline $\begin{array}{c}\text { HRCT Fibrosis } \\
\text { Score }\end{array}$ & 0.32 & 0.24 & 0.13 & 0.63 & 0.04 & 0.89 & -0.07 & 0.79 \\
\hline $\begin{array}{c}\text { HRCT } \\
\text { Combined } \\
\text { score }\end{array}$ & -0.22 & 0.43 & -0.33 & 0.22 & -0.26 & 0.35 & -0.26 \\
\hline
\end{tabular}

Table 4. Spearman correlation coefficient between HRCT radiology

\begin{tabular}{|c|c|c|c|}
\hline FVC (L) & P & FVC \% predicted & p \\
\hline HRCT GGO Score & -0.23 & 0.42 & -0.07 \\
\hline HRCT Fibrosis score & 0.03 & 0.9 & -0.32 \\
\hline HRCT Composite score & -0.37 & 0.17 & 0.8 \\
\hline
\end{tabular}

\section{Discussion}

In a group of patients with concomitant diffuse parenchymal lung disease and pulmonary hypertension, we found that there was not a significant change in diffusion capacity and 6minute walk distance after administration of a single dose of sildenafil. Diffusion capacity measured before and after sildenafil, did not correlate with imaging scores that reflect burden of parenchymal disease.

The approach to pulmonary hypertension in patients with diffuse parenchymal lung disease remains controversial. The main theoretical concern for administering pulmonary arterial vasodilator therapy has been worsening of ventilation perfusion matching due to release of hypoxic vasoconstriction. Nevertheless, in the only study which addressed the effect of sildenafil on gas exchange [3], Ghofrani et al. observed improvement in ventilation perfusion matching in eight patients with interstitial lung disease using the multiple inert gas elimination technique (MIGET). Other small clinical trials have also demonstrated modest hemodynamic and functional improvement in this group of patients $[12,13]$. More recently, the post hoc analysis of the SUPER Trial [4] and the Step-IPF trial [6], demonstrated that patients with parenchymal lung disease and pulmonary hypertension improved their 6 minute walk distance after twelve weeks of treatment with sildenafil. Furthermore, Step-IPF trial demonstrated significant improvement in diffusion capacity in the group of patients who received sildenafil compared with control. The mechanism of action for sildenafil in these cases is unclear. Snyder and colleagues [14], analyzed the effect of this medication on DLCO and its components in healthy subjects. When fourteen subjects were exposed to acute resting and exertional hypoxia, sildenafil improved alveolar-capillary membrane conductance relative to pulmonary capillary volume (DM/ 
Mira-Avendano I (2017) Acute effect of oral sildenafil on diffusion capacity measurements in patients with diffuse parenchymal lung disease and pulmonary hypertension

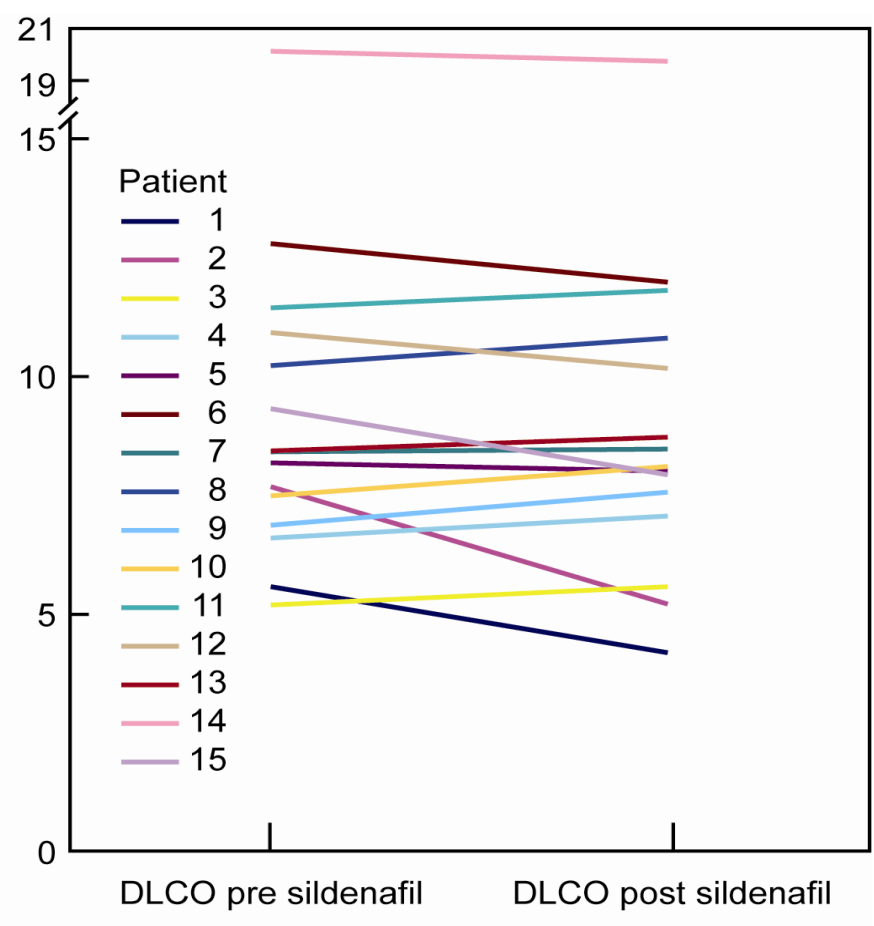

Figure 1. Changes in DLCO $(\mathrm{ml} / \mathrm{min} / \mathrm{mmHg})$ after sildenafil $(\mathrm{n}=15)$

$\mathrm{Vc}$ ) in comparison with placebo suggesting a direct salutary effect on alveolar capillary membrane function. However, overall effect on DLCO was not significant in this study.

When clinicians encounter a decrease in diffusion capacity in patients with diffuse parenchymal lung disease, progression of disease and/or the presence of pulmonary hypertension are primary considerations. Severe decrements in diffusion capacity in the presence of parenchymal lung disease may signify presence of pulmonary hypertension and also provide a means for follow up of these patients. Lettieri and colleagues[1] reported 10.2 times higher likelihood of pulmonary hypertension among patients with idiopathic pulmonary fibrosis whose DLCO was less than $40 \%$ predicted. In this cohort, diffusion capacity was the only independent variable associated with increased mortality. Similarly, Hamada and colleagues [2] found that decreased DLCO was the only statistically significant parameter related to survival in idiopathic pulmonary fibrosis. In our study, lack of correlation between imaging scores that reflect severity of parenchymal disease and diffusion capacity support the notion that the decrease in DLCO is more closely related to the vascular pathology than the parenchymal disease in these patients with both conditions.

In conclusion, our study found no acute change in diffusion capacity after a single dose of oral sildenafil. While we would caution clinicians for rare exceptions to these findings, we believe our data exclude a significant confounding effect in interpretation of diffusion capacity in patients with parenchymal lung disease who are treated for pulmonary hypertension with oral sildenafil. Whether this conclusion holds true at higher doses of sildenafil and in patients with vasodilator response may offer further venues for research.

\section{Competing interests}

The authors declare that they have no competing interests.

\section{Authors' contributions}

IM: makes contribution in the conception and design of the trial, patient recruitment, analysis and interpretation of data and drafted the manuscript.

UH: participates in the conception and design of the trial and revising the manuscript with important intellectual contribution.

CS: participated in conception and design of the trial and patient recruitment.

DL: carried out the responsibility of make the DLCO measurement and contributed with data interpretation.

RY: made the interpretation of all the Chest CT images and contributed with data interpretation.

RD: participates in the trial design, revised the article and made the final approval of the version to be submitted.

\section{Acknowledgments}

Kay Stelmach, RN, who made an important contribution helping with the acquisition of data.

Meng Xu, MS, who cooperated with the analysis and interpretation of data.

\section{References}

1. Lettieri CJ, Nathan SD (2006) Barnett SD Prevalence and outcomes of pulmonary arterial hypertension in advanced idiopathic pulmonary fibrosis. Chest 129: 746-752. [Crossref]

2. Hamada K, Nagai S, Tanaka S (2007) Significance of pulmonary arterial pressure and diffusion capacity of the lung as prognosticator in patients with idiopathic pulmonary fibrosis. Chest 131: 650-656. [Crossref]

3. Ghofrani HA, Wiedemann R, Rose F (2002) Sildenafil for treatment of lung fibrosis and pulmonary hypertension: a randomised controlled trial. Lancet. 360: 895-900. [Crossref]

4. Badesch DB, Hill NS, Burgess G (2007) Sildenafil for pulmonary arterial hypertension associated with connective tissue disease. J Rheumatol. 34: 2417-2422. [Crossref]

5. Rubin LJ, Badesch DB, Fleming TR (2011) Long-term treatment with sildenafil citrate in pulmonary arterial hypertension: the SUPER-2 study. Chest. 140: 1274-1283. [Crossref]

6. Zisman DA, Schwarz M (2010) Idiopathic Pulmonary Fibrosis Clinical Research Network, A controlled trial of sildenafil in advanced idiopathic pulmonary fibrosis. $N$ Engl J Med. 363: 620-628. [Crossref]

7. American Thoracic Society, European Respiratory Society. American Thoracic Society/ European Respiratory Society International Multidisciplinary Consensus Classification of the Idiopathic Interstitial Pneumonias. This joint statement of the American Thoracic Society (ATS), and the European Respiratory Society (ERS) was adopted by the ATS board of directors, 2001 and by the ERS Executive Committee, June 2001. Am J Respir Crit Care Med. 2002. 165: 277-304. [Crossref]

8. Miller A, Thornton JC, Warshaw R (1983) Single breath diffusing capacity in a representative sample of the population of Michigan, a large industrial state. Predicted values, lower limits of normal, and frequencies of abnormality by smoking history. $\mathrm{Am}$ Rev Respir Dis. 127: 270-277. [Crossref]

9. Macintyre N, Crapo RO, Viegi G (2005) Standardisation of the single-breath determination of carbon monoxide uptake in the lung. Eur Respir J. 26: 720-735. [Crossref]

10. ATS Committee on Proficiency Standards for Clinical Pulmonary Function Laboratories (2002) ATS Committee on Proficiency Standards for Clinical Pulmonary Function Laboratories. ATS statement: guidelines for the six-minute walk test. Am J Respir Crit Care Med. 166: 111-117. [Crossref]

11. Kazerooni EA, Martinez FJ, Flint A (1997) Thin-section CT obtained at 10-mm increments versus limited three-level thin-section CT for idiopathic pulmonary fibrosis: correlation with pathologic scoring. AJR Am J Roentgenol. 169: 977-983. [Crossref]

12. Collard HR, Anstrom KJ, Schwarz MI (2007) Sildenafil improves walk distance in idiopathic pulmonary fibrosis. Chest 131: 897-899. [Crossref] 
Mira-Avendano I (2017) Acute effect of oral sildenafil on diffusion capacity measurements in patients with diffuse parenchymal lung disease and pulmonary hypertension

13. Madden BP, Allenby M, Loke TK, Sheth A (2006) A potential role for sildenafil in the management of pulmonary hypertension in patients with parenchymal lung disease. Vascul Pharmacol 44: 372-376. [Crossref]
14. Snyder EM, Olson TP, Johnson BD (2008) Influence of sildenafil on lung diffusion during exposure to acute hypoxia at rest and during exercise in healthy humans. Eur $J$ Appl Physiol 103: 421-430. [Crossref]

Copyright: (C2017 Mira-Avendano I. This is an open-access article distributed under the terms of the Creative Commons Attribution License, which permits unrestricted use, distribution, and reproduction in any medium, provided the original author and source are credited. 